\title{
Development of new polymeric membranes for ENFETs for biomedical and environmental applications
}

\author{
N. Jaffrezic-Renault*, K. Wan, A. Senillou, J.-M. Chovelon and C. Martelet \\ Laboratoire d'Ingénierie et Fonctionnalisation des Surfaces UMR CNRS 5621, École Centrale de Lyon, BP163, 69131 Ecully Cedex, France
}

Two ways have been investigated for the preparation of urea ENFETs : covalent bonding of urease directly on the surface of an ammonium sensitive FET and control of the diffusion of charged species into the enzymatic layer on pH-ISFET using additional charged polymeric membranes. Trichlorfon as a representative pesticide is detected using a BuChE-FET sensor which is prepared either with cross-linked BSA-glutaraldehyde membrane or photocross-linkable PVA/SbQ (poly(vinyl alcohol) containing styrylpyridinium) membrane.

\section{Introduction}

The urea determination is of great interest in biomedical and clinical analysis applications. The determination of urea in biological serum has been yet realized with biosensors. Most of these biosensors are based on the immobilization of urease, an enzyme which catalyses the hydrolysis of urea according to the reaction:

$$
\left(\mathrm{NH}_{2}\right)_{2} \mathrm{CO}+2 \mathrm{H}_{2} \mathrm{O}+\mathrm{H}^{+} \stackrel{\text { urease }}{\longrightarrow} 2 \mathrm{NH}_{4}^{+}+\mathrm{HCO}_{3}^{-}
$$

Among these biosensors, the ENFET (ENzyme Field Effect Transistor) is based on the ISFET (Ion Sensitive Field Effect Transistor) the urease enzyme being immobilized onto the surface of the gate insulator. The advance in semiconductor technology in the last few years has allowed to develop this type of sensor. For the determination of urea, two methods of detection have been exploited with ENFET. Either detection of $\mathrm{pH}$ changes due to the enzymatic reaction was mea- sured around the gate surface of a pH-FET [1-7] or detection of $\mathrm{NH}_{4}^{+}$ions enzymatically formed was obtained with an ammonium ion sensitive FET [7, 8].

For the pH-FET and the $\mathrm{NH}_{4}^{+}$-ISFET, the immobilization of the enzyme molecules was carried out by a cross-linking process. Unfortunately, this method induced a loss of the protein flexibility and hence an unactivation of the immobilized enzyme. High stability, good sensitivity and short response time are mainly dependent on the method of enzyme immobilization and on the thickness of the resulting biological layer. In order to obtain these characteristics and to improve the mechanical stability of the immobilized enzyme, we have investigated the potentialities of a chemical grafting of the enzyme molecules directly on the ammonium sensitive membrane [9]. It was expected that this approach could improve the accessibility to enzyme molecules and hence the sensitivity of the biosensor.

With the pH-FET biosensor, the membrane containing urease was directly deposited onto the sensitive area of the sensor. In this paper, the influence of additional charged polymeric membranes on the diffusion of charged species into the enzymatic layers on the characteristics of these ENFETs was studied.

Since pesticides are among the most toxic products of the chemical industry, a strong demand for disposable, low cost and simple monitoring devices exists. In this context, biosensors seem to be a promising tool. In this case, the scheme for the detection of the pesticides was associated with their ability to inhibit one enzyme such as the acetylor butyrylcholinesterase (AcChE or BuChE). Normally AcChE and BuChE hydrolyze acetylcholine chloride and butyrylcholine chloride, while acid and choline species are formed.

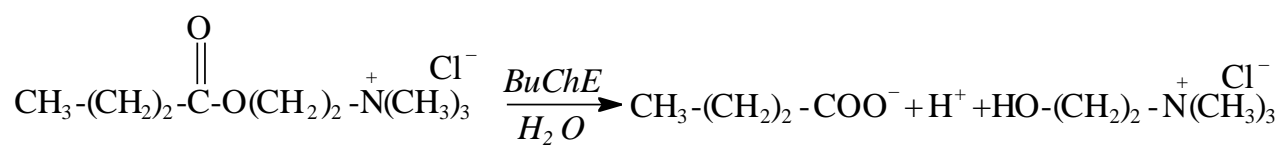

butyrylcholine chloride

butyric acid

choline

For the detection of trichlorfon which leads to the inhibition of the enzyme (cf. the following reaction), the responses of the BuChE biosensors were compared with and without it. 


$$
\begin{aligned}
& \mathrm{O} \quad \mathrm{O}
\end{aligned}
$$

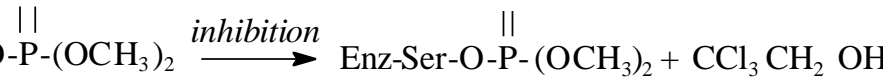

To reactivate the inhibited enzyme, a method also used by C. Cremisini [16] was employed. The phosphorylated enzymatic biosensor was immersed for a given time in a stirred reactivation solution $(0.1 \mathrm{M}$ of PAM-2 in a $0.1 \mathrm{M}$ phosphate buffer at $\mathrm{pH}=7$ ).

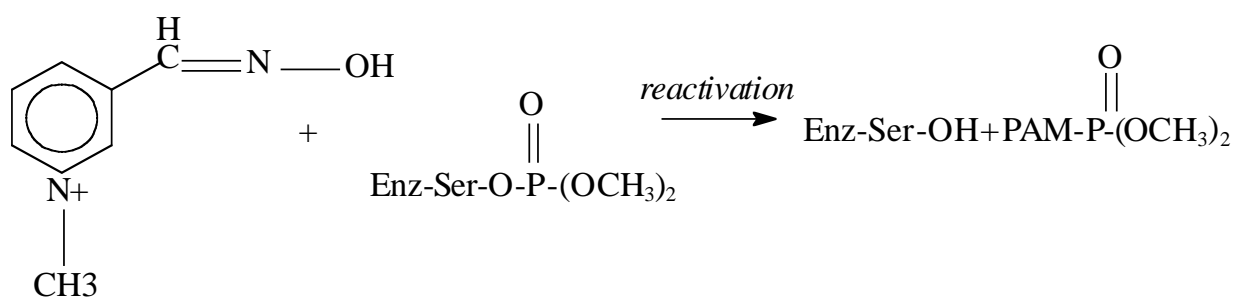

In the case of electrochemical biosensors, products of these reactions are usually detected with amperometric $[10,11]$, potentiometric $[12,13]$, and conductimetric [14] electrodes. Concerning potentiometric detection, Ion Sensitive Field Effect Transistors (ISFET), represent one interesting alternative, although a few works have been devoted to them $[12,13,15]$.

The basic requirements for a reliable biosensing probe are its sensitivity, linearity, response time, reproducibility and long lifetime. These parameters are usually controlled by immobilization procedure and the sensitivity of the basic electrochemical sensor. Up to now, works dealing with ISFET have shown either a low reproducibility [13] and/or a short lifetime $[13,14]$, probably due to the immobilization procedure used.

In this work, the performances of the ISFETs using two different immobilization procedures have been compared. In

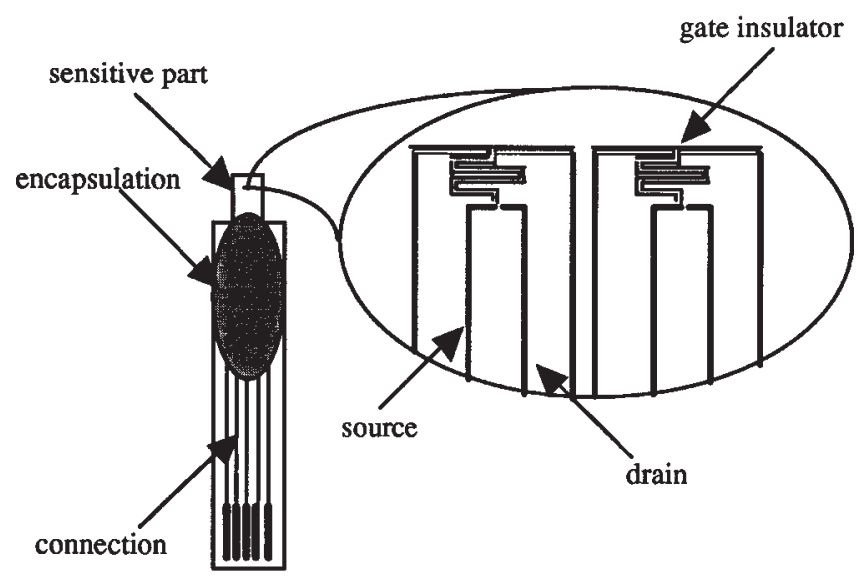

Figure 1. Schematic view of the ISFET based microsensor. the first case, a cross-linking procedure with BSA-glutaraldehyde was used, while in the second one, enzymes were immobilized by entrapment in polyvinylalcohol bearing styrylpyridinium groups. This later material membrane was tested for the first time on ISFET and seems very interesting because it is known that this kind of immobilization can preserve the native properties of the entrapped enzyme, as there is no covalent linkage to the biocatalyst molecule [16].

\section{Experimental}

\section{Materials}

\section{ISFET sensors}

n-Channel depletion-mode ISFETs were fabricated at the Research Institute of Microdevices (Kiev, Ukraine) on a p$\mathrm{Si}$ wafer with a (100) crystal orientation and $7.5 \mathrm{Ohm} . \mathrm{cm}$ was made by ion implantation of phosphorus, the implanted amount depended on the threshold voltage required. In the experiments ISFETs with a channel length of $20 \mu \mathrm{m}$ and with a threshold voltage of about $-3 \mathrm{~V}$ were used.

Sensor chips including two ISFETs (cf. figure 1), were glued on a ceramic support made of fused alumina measuring $28 \mathrm{~mm} \times 6 \mathrm{~mm}$ (thickness $1.0 \mathrm{~mm}$ ). The sensor contact pads were electrically bonded by ultrasonic wiring to aluminum conducting paths which were photolithographically patterned on the ceramic support. After wiring, the contact pads and wires were encapsulated with epoxy resin. Details about the construction and operation of the ISFETs can be found in reference [17].

\section{Solutions and reagents}

Nonactin from streptomyces tsusimaensis, diisononyl phtalate (DNP approx. 80\%) and tetrahydrofuran (THF >99\%) 
were purchased from Sigma. Solutions of ammonium, sodium, potassium, copper and mercury chloride were obtained from salts (from Sigma and Prolabo, ACS reagents) diluted in bidistilled water. Polyvinylchloride (PVC) was purchased from Solvay and carboxylated polyvinylchloride (PVC-COOH) from Aldrich.

Urease (EC 3.5.1.5. type VI from "Jack beans", $118 \mathrm{U} / \mathrm{mg}$ ), glutamic dehydrogenase (EC 1.4.1.3. type III from bovine liver $40 \mathrm{U} / \mathrm{mg}$ ), 1-ethyl-3-(3-dimethylaminopropyl)-carbodiimide (EDAC), $\alpha$-ketoglutaric acid, nicotinamide adenine dinucleotide reduced form (NADH), dithiothreitol, sodium azoture $\left(\mathrm{NaN}_{3}\right)$, glycerol and EDTA were purchased from Sigma. Poly(4-vinylpyridine-co-styrene) (PVPy) powder (product 19,207-4) and Nafion (product 27,470-4) were purchased from Aldrich. Butyrylcholinesterase (BuChE) (EC 3.1.1.8., 10-20 $\mathrm{U} \mathrm{mg}^{-1}$, Pseudocholinesterase, from horse serum), Bovine serum albumin (BSA), trichlorfon, butyrylcholine chloride and PAM-2 (pyridine -2aldoxime methiodide) were also purchased from Sigma (France). PVA-SbQ (SPP-H-13) was given kindly as gift by Toyo Gosei Kogyo Co. (Japan). 25\% V/V glutaraldehyde (GA) solution was from Fluka (Buchs, Switzerland). All of the other reagents were of analytical grade.

\section{Measurements}

The output voltage of the modified ISFETs immersed in double-distilled water were measured with the source and drain follower type ISFET amplifier. This system allowed the source voltage (Vs) to be measured while the drain current (Id) and the drain voltage ( $\mathrm{Vd})$ remained constant. $(\mathrm{Vd}=1 \mathrm{~V}, \mathrm{Id}=100 \mu \mathrm{A})$. Vs was directly plotted on a recorder.

- individual

The voltage was measured against a platinum electrode

- differential

Two ISFETs were connected to two identical amplifiers : output signals Vs and Vs' were measured against the common silicon substrate. A differential amplifier enabled the difference of these two signals to be obtained as well.

All the measurements were carried out at $22 \pm 2^{\circ} \mathrm{C}$.

\section{Ammonium-sensitive FET fabrication}

\section{Composition of the PVC membranes}

- $\mathrm{NH}_{4}^{+}$-ISFET:

For the preparation of the membrane of the $\mathrm{NH}_{4}{ }^{+}$ISFET, a typical procedure was applied using PVC-COOH and DNP in a ratio of 7:3 (w/w) diluted in THF, with $3 \%$ of nonactin as ionophore.

\section{- REFET:}

The REFET is an ISFET non sensitive to ammonium ions which allows to work in a differential mode. The non sensitive FET membrane was elaborated with polyvinylchloride without nonactin. The composition of the REFET membrane was PVC and DNP in a ratio of 3:7(w/w) diluted in THF. In order to avoid any coupling of the urease on the REFET surface, the polymeric matrix was PVC and not PVC$\mathrm{COOH}$.

\section{Deposition of the PVC and PVC-COOH membranes}

Before deposition of the PVC membranes, a surface treatment was performed: the ISFET insulator surface was treated with HMDS (hexamethyldisilazane) in order to functionalize surface sites (hydroxyl groups). This treatment allows to neutralize the acid base properties of these sites and thus to obtain a blocking insulator/PVC interface. Moreover, the hydrophobic methyl groups at the grafted surface insure a good adhesion of the PVC membrane. This type of treatment can avoid the use of an intermediate hydrogel layer as it was recommended by Bergveld et al [18] in order to eliminate the effect of $\mathrm{CO}_{2}$ diffusion on the surface charge of the insulator.

Next, the plasticized PVC membranes were formed by depositing $0.5 \mu \mathrm{l}$ of each of the previous solutions on the surface of one ISFET (for differential measurement) and the solvent was evaporated under nitrogen flow.

\section{Preparation of the enzymatic membranes}

\section{Urease membrane onto ammonium-sensitive FETS}

Once ammonium-sensitive FET realized, it was soaked in a solution containing $10 \mathrm{mg} / \mathrm{ml}$ of urease and $4 \mathrm{mg} / \mathrm{ml}$ of carbodiimide and left for 12 hours. Then, the sensor was soaked, during one hour, in a $5 \mathrm{mM}$ phosphate buffer $\mathrm{pH} 7.4$ solution vigorously stirred in order to eliminate adsorbed enzyme molecules. It was shown [19] that using this procedure, no urease was covalently bonded onto the REFET surface and $53 \mathrm{mU} . \mathrm{cm}^{-2}$ of urease was grafted on the ammonium sensitive FET corresponding to an apparent specific activity of $50 \%$ of the free enzyme.

\section{Butylcholinesterase and urease membranes onto $\mathrm{pH}$ ISFETS}

BSA enzymatic membrane: a mixture of $5 \mathrm{mg}$ BSA, $5 \mathrm{mg}$ urease or BuChE, $10 \mu \mathrm{l}$ of glycerol in $90 \mu \mathrm{l}$ of phosphate buffer $(1 \mathrm{mM}, \mathrm{pH} 8.0)$ was prepared. Then glycerol was used as a plasticizer to avoid the formation of cracks in the enzymatic membrane during storage and also to result in a better homogeneity of the membrane and better adhesion to the surface of the transducer. $0.5 \mu \mathrm{l}$ of this mixture was deposited on the sensitive area of a FET. Then the sensor chips were placed in a saturated glutaraldehyde vapor for $30 \mathrm{~min}$.

PVA/SbQ enzymatic membrane: a mixture of $45 \mathrm{mg}$ $\mathrm{PVA} / \mathrm{SbQ}, 5 \mathrm{mg} \mathrm{BuChE}$ in $50 \mathrm{mg}$ phosphate buffer $(1 \mathrm{mM}$, $\mathrm{pH}$ 8.0) was prepared. $0.5 \mu \mathrm{l}$ of this mixture was deposited on the sensitive area of a FET. Then, the sensor chips were exposed under UV light for $25 \mathrm{~min}$.

The REFET was the reference ISFET working in the differential measurement mode. The membrane of the REFET 
used with BSA-ENFET was a mixture of $10 \mathrm{mg}$ of BSA, $10 \mu \mathrm{l}$ of glycerol in $90 \mu \mathrm{l}$ of phosphate buffer $(1 \mathrm{mM}, \mathrm{pH} 8.0)$. $0.5 \mu \mathrm{l}$ of this mixture was deposited on the insulator surface of the REFET. Then the sensor chips were placed in a saturated glutaraldehyde vapor for $30 \mathrm{~min}$. The REFET used for the PVA/SbQ-ENFET was prepared by depositing $0.5 \mu \mathrm{l}$ of a mixture of $50 \mathrm{mg}$ of PVA/SbQ and $50 \mathrm{mg}$ of phosphate buffer ( $1 \mathrm{mM}, \mathrm{pH} 8.0)$ on the insulator surface of the REFET and then exposed under UV light for $25 \mathrm{~min}$.

\section{Additional polymeric membranes onto urease ENFETs}

A drop of a solution (about $0.1 \mu \mathrm{l}$ ) containing $10 \mathrm{w} / \mathrm{w} \%$ urease in $5 \mathrm{mM}$ Tris- $\mathrm{HNO}_{3}$, pH 7.4 was deposited onto the sensitive area of an ISFET and dried at room temperature for $3 \mathrm{~min}$. Then the bioselective material was covered with $\mathrm{x} \mu \mathrm{l}$ of a $0.5 \%$ polymer (PVPy or Nafion) solution in ethanol and dried in air for $5 \mathrm{~min}$. In this case, through such immobilization process, two effects have been achieved: a) enzyme molecules were not cross-linked and were in a free configuration; b) enzyme was covered with a charged polymeric material (PVPy or Nafion), which was already used for an additional membrane preparation in potentiometric sensors $[2,20]$.

For the REFET, urease was replaced by BSA.

\section{Measuring procedure for the pesticide detection .}

ENFET and REFET were immersed in $10 \mathrm{ml}$ of $1 \mathrm{mM}$ phosphate buffer $(\mathrm{pH} 8.0)$ at room temperature under magnetic stirring system. The substrate concentration $(\mathrm{BuChCl})$ was varied by addition into the vessel of aliquots, so that a final concentration of substrate close to $20 \mathrm{mM}$ was reached. For each addition, an increase of $\mathrm{H}^{+}$concentration in enzymatic membrane is produced due to the enzymatic reaction which leads to the hydrolysis of the substrate. The steady state was obtained within $30 \mathrm{~s}$ and all the results have been done $1 \mathrm{~min}$ after each injection.

For the kinetic response, the maximum slope of the response curve versus time was measured. For both the kinetic and stationary modes, three measurements for each experimental point were done.

The procedure for the evaluation of the effect of the enzyme activity inhibition by pesticides on the biosensors response includes the following steps:

1. The biosensor was soaked in a $1 \mathrm{mM}$ phosphate buffer solution until reaching the stable baseline output signal.

2. $\mathrm{BuChCl}$ was added to the measurement cell until a fixed final concentration $(20 \mathrm{mM}$ in our case). The corresponding steady-state output signal of the biosensor was taken as an index of the catalytic signal of the immobilized enzyme, and such a value of the biosensor response was used for further evaluation of the inhibition effect of a definite pesticide.

3. After washing, the sensor was incubated for 10 to 60 minutes in the solution of tested pesticide.
4. After extensive washing with the working buffer, the steady-state response of the biosensor was determined.

The level of inhibition due to the action of a definite pesticide was evaluated by comparison of the steady-state levels of the biosensor before and after treatment with a pesticide solution. To reactivate the inhibited enzyme, the biosensor was immersed for 10 to 60 minutes in a vigorously stirred reactivation solution consisting of a saturated solution of Pyridine-2-aldoxime methiodide (PAM-2) in PBS.

\section{Results and discussion}

\section{Analytical characteristics of the ammonium-sensitive FETs}

Figure 2 shows the response of the REFET and the $\mathrm{NH}_{4}^{+}$ ISFET for the two modes of measurement to $\mathrm{NH}_{4}^{+}$concentration in the range $10^{-7}-10^{-3} \mathrm{M}$.

The REFET sensor, made of $\mathrm{PVC}$ is insensitive to $\mathrm{NH}_{4}^{+}$ until $0.1 \mathrm{mM}$ while a response $\left(20 \mathrm{mV} / \mathrm{pNH}_{4}^{+}\right)$is observed for higher concentrations. This behavior shows that the potential difference at the water/plasticized PVC interface is influenced by the concentration of the ammonium ion, the partition coefficient of this ion in plasticized PVC being not nil [21]. This phenomenon is due to the cationic permselectivity through anionic defects of the PVC. It should be noted that the REFET sensitivity to $\mathrm{NH}_{4}^{+}$should be markedly reduced if the $\mathrm{NH}_{4}^{+}$source is spatially restricted to the urease membrane deposited on the ISFET.

In the normal mode, the calibration curve is linear in the range of concentration $10^{-5}-10^{-3} \mathrm{M}$, the $\mathrm{NH}_{4}^{+}$-FET response being quasi Nernstian with a slope of about $56 \mathrm{mV} / \mathrm{pNH}_{4}^{+}$.

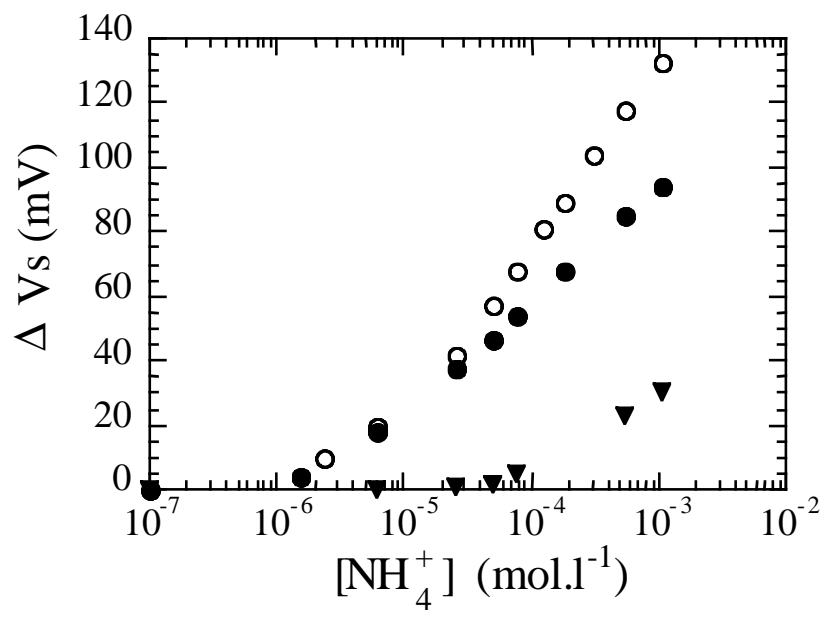

Figure 2. Sensitivity of the ammonium ISFET in the two modes of measurements and that of the REFET in double distilled water : $\bigcirc$ normal mode, differential mode, $\nabla$ REFET. 
A less sensitive response $\left(23 \mathrm{mV} / \mathrm{pNH}_{4}^{+}\right)$is recorded for lower concentrations.

As expected, in the differential mode, the value of the $\mathrm{NH}_{4}^{+}$-FET response $\left(36 \mathrm{mV} / \mathrm{pNH}_{4}^{+}\right)$is diminished because the signal of REFET is substrated from the signal of the sensitive FET. This sensitivity decrease is counterbalanced by a slight increase in the linear range of the calibration curve $\left(6 \times 10^{-6}-1 \times 10^{-3} \mathrm{M}\right)$ the detection limit being $2 \mu \mathrm{M}$. The response time (determined as the time required to reach a steady-state potential value after a $\mathrm{NH}_{4}^{+}$injection) was within 30s. Consequently, the differential mode was used for the subsequent investigations. Effectively this type of measurement allows to increase the selectivity of the sensor for $\mathrm{NH}_{4}^{+}$ions and to suppress the utilization of the reference electrode as previously reported in [22]. In order to investigate the repeatability of the $\mathrm{NH}_{4}^{+}$-FET response, ten successive calibration curves in the $\mathrm{NH}_{4}^{+}$range $10^{-5}-10^{-3} \mathrm{M}$ were recorded in the differential mode with the same sensor. A relative standard deviation of $15 \%$ was observed.

\section{Analytical characteristics of the urea sensor based on ammonium-sensitive FETs}

Ammonium ions enzymatically produced at the interface sensitive membrane/solution do not affect the response of the REFET. So, as expected, the biosensor sensitivity for urea is identical $(50 \mathrm{mV} / \mathrm{pUrea})$ with the two modes of measurement, the detection limit being $2 \mu \mathrm{M}$ (Fig. 3). This detection limit is markedly lower than those $(50-100 \mu \mathrm{M})$ previously reported for $\mathrm{pH}$-FET biosensors [1,2] and similar to the value $(1 \mu \mathrm{M})$ recently obtained with potentiometric biosensors [23]. It appears clearly that the better detection limit is obtained when the detected specie is $\mathrm{NH}_{4}^{+}$. This may be attributed to the procedure used for urease immobilization. The chemical grafting of enzyme on the carboxylic groups of the PVC-COOH coating does not deteriorate the ammonium sensitivity of this membrane whereas the crosslinking method decreases the $\mathrm{H}_{3} \mathrm{O}^{+}$sensitivity [24].

It should be noted that the influence of the ionic strength on the response of the urea sensor is the same that previously obtained with the ammonium sensor. A loss of sensitivity of $55 \%$ is observed between a calibration curve recorded in a $1 \mathrm{mM} \mathrm{NaCl}$ solution and one in PBS solution.

The ENFET sensors were also examined for the storage and operational stabilities. The biosensor sensitivity (48 \pm $5 \mathrm{mV} /$ pUrea) was approximately constant during 15 days. However, a detachment of the enzymatic membrane is observed after 15 days, inducing a complete loss of the ENFET sensitivity for urea.

The operational stability of the sensor was checked at room temperature through the stability of biosensor response to $100 \mathrm{mM}$ urea. No appreciable change in the steady-state voltage response of the biosensor was observed after 3 hours, illustrating the good stability of the ENFET.

The ENFET construction was also quite reproducible: eight ENFETs were prepared by following identical chemical steps and their responses towards urea were investigated. The comparison of the sensitivity determined from the resulting calibration curves indicates that the relative standard deviation is only $10 \%$.

\section{Analytical characteristics of the urea sensor based on pH-ISFETs. Effect of additional polymeric membranes}

Biosensors with urease immobilized into a BSA matrix present a rapid response when urea is added (1-2 min) and exhibit a quasi linear "voltage-concentration" dependence from $50 \mu \mathrm{M}$ up to $2 \mathrm{mM}$ urea (Fig. 4, curve 1). Thus, to conduct measurements in real biological or food samples with a high urea content (5-7 $\mathrm{mM}$ urea concentration in the human

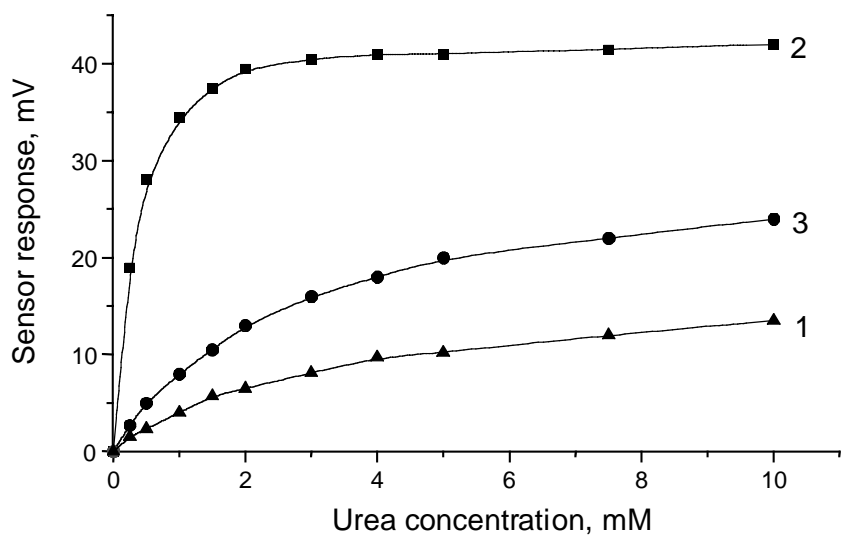

Figure 4. Calibration curves of urea sensitive ENFETs with urease immobilised in a BSA matrix (1) and under Nafion (2) or PVPy (3) membranes. Measurements were done in a $10 \mathrm{mM}$ phosphate buffer, pH 7.4.
Figure 3. Sensitivity of the urea ISFET in the two modes of measurements in double distilled water, at $\mathrm{pH} 7.4: 0$ differential mode, $\bigcirc$ normal mode. 
blood, for example), such a sample has to be diluted with a proper buffer in optimal proportions. Such a dilution does not only shift the urea concentration into the sensitive range (concentrations corresponding to the linear part of the calibration curve), but also reduce the variations in $\mathrm{pH}$ and ionic strength that can in some way influence the sensor response.

The specificity of potentiometric sensors is strongly dependent on the buffer concentration $[2,20]$. If measurements are carried out in a sample with a high buffer capacity, the modifications of $\mathrm{pH}$ induced by the enzymatic reaction are masked by the effect of the buffer capacity. In order to overcome this drawback it was proposed to protect the sensitive biolayer with an additional charged polymeric membrane in order to reduce the diffusion of the buffer species into the biomatrix. It has been shown $[2,20]$ that the presence of a charged polymeric membrane is sufficient to suppress the buffer influence on the sensor performance and gives possibility to conduct measurements even in high buffered medium. Moreover, experimental data shown in Fig. 4 (curves 2 and 3) and detailed analysis of the initial regions of calibration curves demonstrate that the main characteristics of the urease biosensor, such as sensitivity to urea and detection limits, can be improved by the use of charged additional membranes (see Table I). Thus, in the case of the ENFETs with urease immobilised under Nafion and PVP membranes, their sensitivity to urea increases in about 5-10 times, in comparison to the biosensors with urease immobilized into BSA membrane and these additional membranes have increased significantly the storage stability of the ENFETs (see Table I).

\section{Calibration of the BuChE FET sensors}

The biosensor calibration curves were presented following two basic methods : first, the steady-state sensor response was registered (Fig. 5a and 6a) and secondly, the kinetic

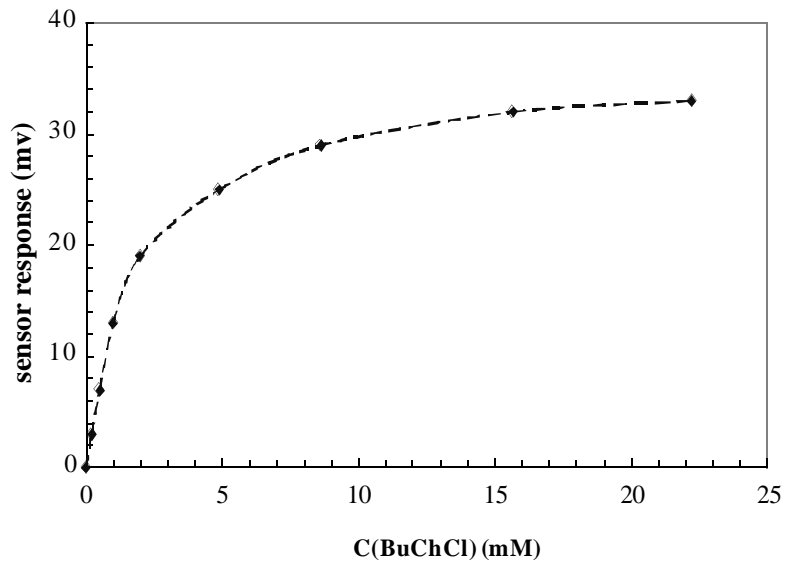

(a)

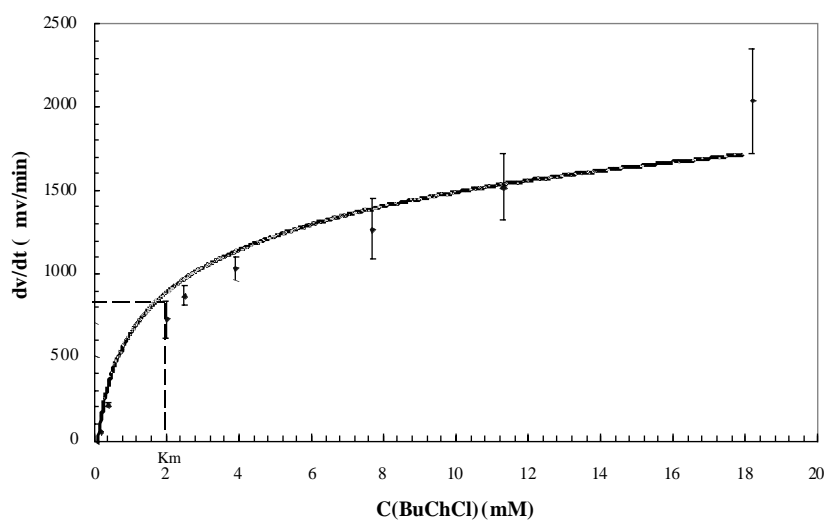

(b)

Figure 5. Calibration curves for BuChE-BSA FET in $1 \mathrm{mM}$ phosphate buffer $\mathrm{pH}=8$. (a) stationary mode ; (b) kinetic mode.

Table I. Main working characteristics of urea sensitive biosensor (urea concentrations were measured in $10 \mathrm{mM}$ buffer solutions, pH 7.4).

\begin{tabular}{|c|c|c|c|c|c|c|c|}
\hline \multirow[t]{2}{*}{ Type of ISFET } & \multirow[t]{2}{*}{$\begin{array}{l}\text { Type of buffer } \\
\text { solution }\end{array}$} & \multirow{2}{*}{$\begin{array}{l}\text { Detection } \\
\text { limit } \\
\text { (M) }\end{array}$} & \multirow{2}{*}{$\begin{array}{l}\text { Sensitivity } \\
\text { (mV/pUrea) }\end{array}$} & \multirow{2}{*}{$\begin{array}{l}\text { Linear part } \\
\text { of dynamic } \\
\text { range }(M)\end{array}$} & \multicolumn{3}{|c|}{$\begin{array}{c}\text { Storage stability } \\
\text { (\% of sensor response) }\end{array}$} \\
\hline & & & & & 10 days & 20 days & 30 days \\
\hline $\begin{array}{l}\text { ammonium-sensitive } \\
\text { ISFET }\end{array}$ & $\begin{array}{l}\text { no buffer } \\
\text { ( } \mathrm{pH}=7.4)\end{array}$ & $2 \times 10^{-6}$ & 50 & $2 \times 10^{-6}-2 \times 10^{-3}$ & 100 & 0 & 0 \\
\hline $\begin{array}{l}\text { pH-ISFET without add. } \\
\text { membrane }\end{array}$ & Phosphate & $5 \times 10^{-5}$ & 4 & $5 \times 10^{-5}-2 \times 10^{-3}$ & 60 & 40 & 20 \\
\hline $\begin{array}{l}\text { pH-ISFET with Nafion } \\
\text { additional membrane }\end{array}$ & Phosphate & $10^{-5}$ & 24 & $10^{-5}-10^{-3}$ & 100 & 100 & 95 \\
\hline $\begin{array}{l}\text { pH-ISFET without add. } \\
\text { membrane }\end{array}$ & Tris & $5 \times 10^{-5}$ & 1.6 & $5 \times 10^{-5}-2 \times 10^{-3}$ & 50 & 30 & 15 \\
\hline $\begin{array}{l}\text { pH-ISFET with PVP } \\
\text { additional membrane }\end{array}$ & Tris & $10^{-5}$ & 5.5 & $10^{-5}-1.5 \times 10^{-3}$ & 90 & 80 & 65 \\
\hline
\end{tabular}

* The biosensors were stored at $4-6^{\circ} \mathrm{C}$ in the same buffer solutions than the one used for testing the sensor responses. 


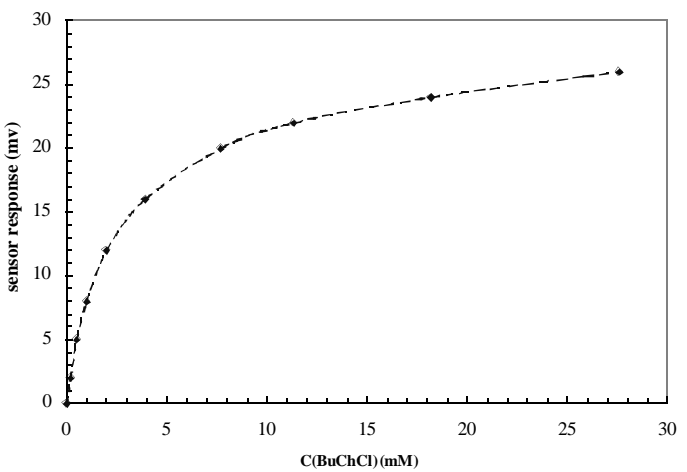

(a)

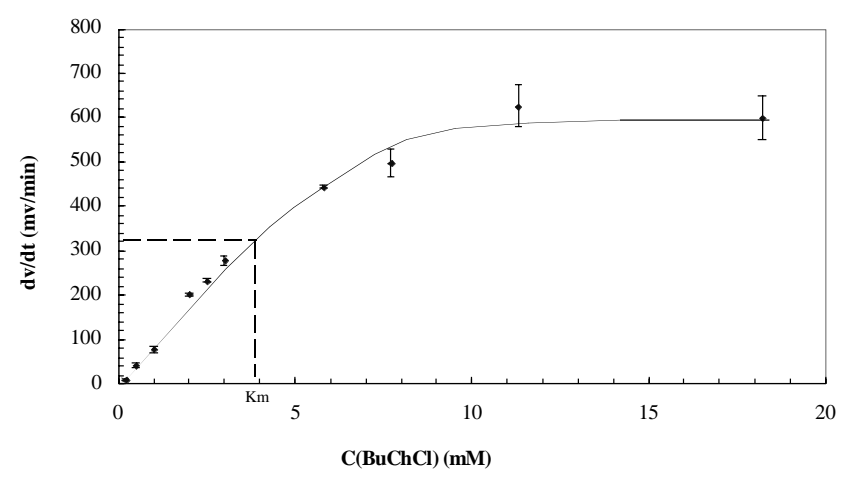

(b)

Figure 6. Calibration curves for BuChE-PVA/SbQ FET in $1 \mathrm{mM}$ phosphate buffer $\mathrm{pH}=8$. (a) stationary mode ; (b) kinetic mode. response (Fig. 5b and 6b). Fig. 5a and 6a show that the dynamic ranges for both membranes are very similar. In addition, a very low standard deviation is obtained for the both curves (less than 1\%). On opposite, the curves obtained in the kinetic mode (Fig. 5b and 6b) show that the dynamic linear ranges differ strongly: 0.2-1 $\mathrm{mM}$ for BSA membrane and $0.2-5.8 \mathrm{mM}$ for PVA/SbQ membrane. For the latter mode, a great standard deviation is obtained (more than $10 \%)$.

In the same way, the apparent Michaelis-Menten constant $K_{m}^{a p p}$ values calculated in kinetic mode are different $(2 \mathrm{mM}$ for BSA membrane and about $3.8 \mathrm{mM}$ for PVA/SbQ membrane). This result can be explained considering the different structures of the enzymatic membrane: in one case the enzyme is cross-linked with BSA while in the second case, the enzyme is entrapped in the photopolymer PVA/SbQ. As a resulting effect, the enzyme is more free in PVA/SbQ membrane than in BSA membrane. It is noteworthy that these values are comparable between themselves, because the same experimental conditions were used; it is known that values of $\mathrm{Km}$ also depend on the ionic strength and $\mathrm{pH}$ of the buffer etc.

\section{Stability of the sensors}

The lifetime of enzymatic membranes constitutes a limiting factor for biosensor applications. In this context, an attempt was made to compare the storage conditions for immobilized enzyme. As one can see in table II, when the biosensors were stored in dry and dark, at $4{ }^{\circ} \mathrm{C}, 80 \%$ of the initial enzymatic activity for PVA/SbQ membrane can be kept after 9 months, while in a phosphate buffer solution $(\mathrm{pH}=8)$ in dark, at $4^{\circ} \mathrm{C}$, the enzymatic activity decreased dramatically

Table II. Effect of storage conditions on the stability of BuChE-FETs. Measurements were carried out with 18mM butyrylcholine choride as substrate in $1 \mathrm{mM}$ phosphate buffer $(\mathrm{pH}=8.0) .100 \%$ is given relative to the value of the first day.

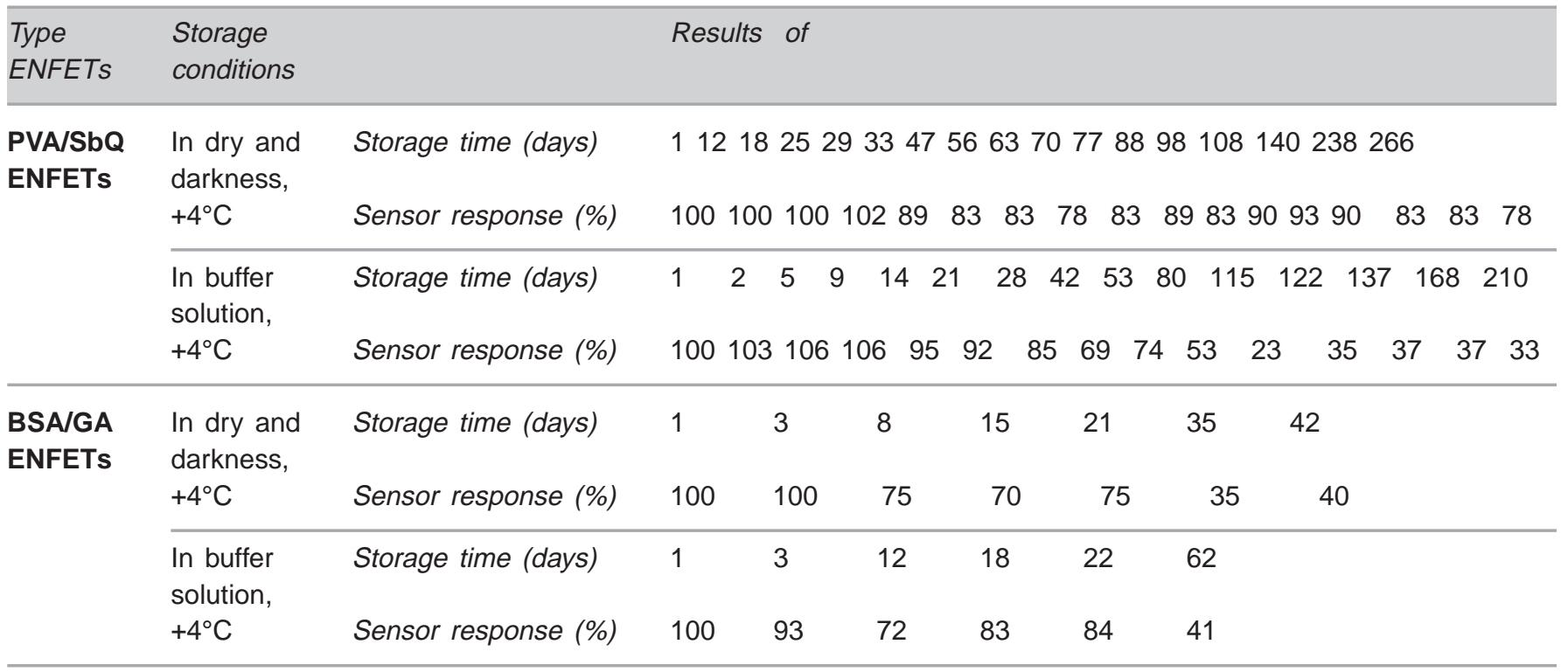




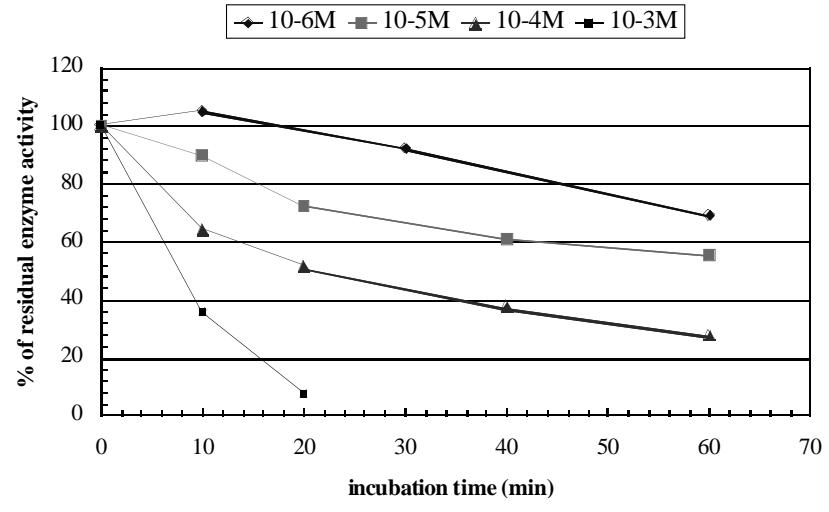

(a)

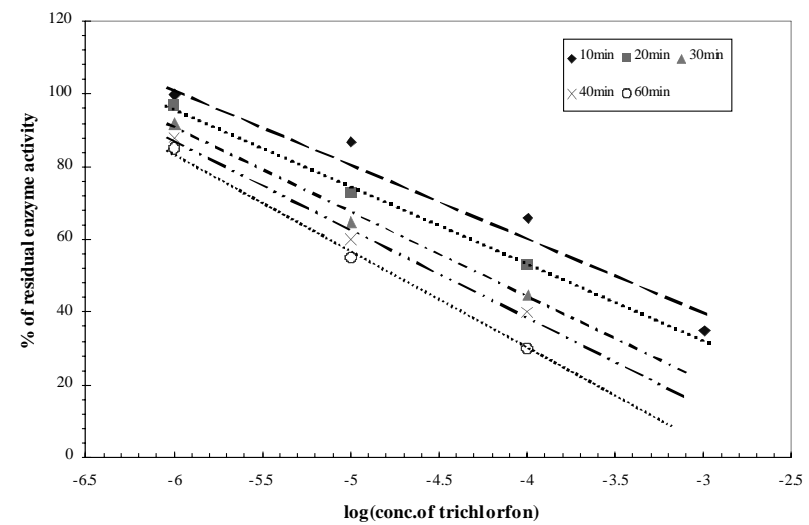

(b)

Figure 7. Inhibition effect on the BuChE-BSA FET sensor by trichlorfon. (a) \% of residual enzyme activity as a function of incubation time ; (b) \% of residual enzyme activity as a function of trichlorfon concentration.

after a storage of 4 months. Such a result can be easily explained, if one remember that one drawbacks of the entrapping method is the possibility of losing enzyme activity, since some pore sizes permit escape of the enzyme. Hence, since the escape of enzymes from the film is more important in buffer solution than in dry, the better results are obtained for the latter.

On the other hand, for the BSA membrane, the enzymatic activity decreased dramatically after a storage of 35 days in dry and dark, at $4{ }^{\circ} \mathrm{C}$ while $80 \%$ of initial enzymatic activity is still maintained after a storage of 42 days in buffer solution at $4{ }^{\circ} \mathrm{C}$ in dark, but after 62 days, only $40 \%$ of the initial enzymatic activity is obtained. Here, the enzymes can not escape from the enzymatic membrane as they are crosslinked in the BSA-glutaraldehyde matrix, except during the first weeks where a loss of a part of the uncrosslinked enzymes from the film can occur.

In this case, for the best storage conditions, a buffer solution is preferred as it allows, among other things, a better

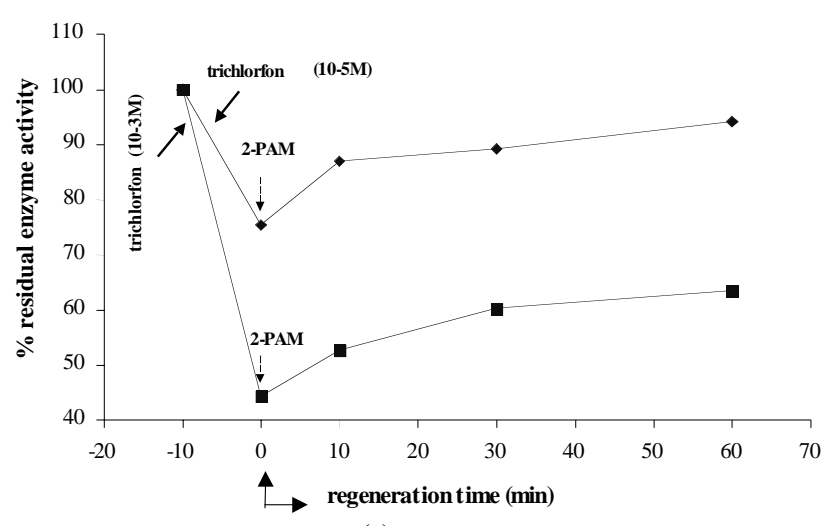

(a)

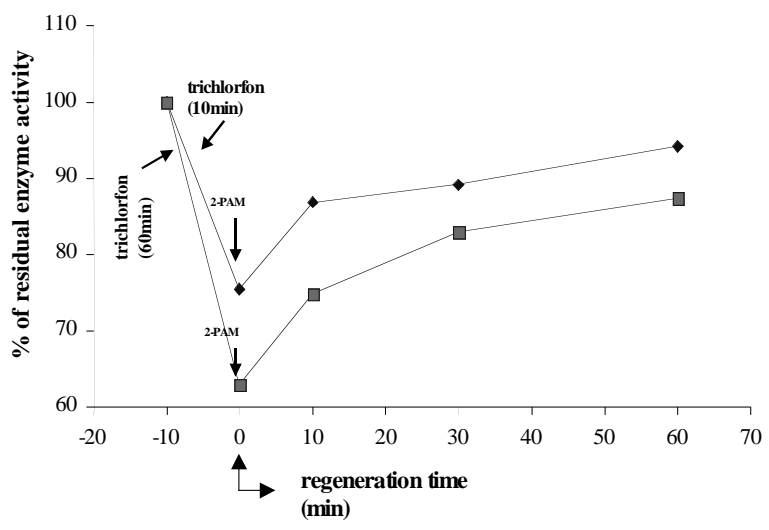

(b)

Figure 8. Recovery of the BSA-BuChE-biosensor response after incubation with trichlorfon by $0.1 \mathrm{~mol} / \mathrm{l}$ of PAM-2 in a phosphate buffer $(\mathrm{pH}=7)$ after (a) incubation for $10 \mathrm{~min}$ at different concentration of trichlorfon and (b) incubation with $10^{-5} \mathrm{M}$ for different inhibition time.

hydrophilic environment around the enzyme, required to avoid its denaturation. Concerning the PVA-SbQ membrane, thanks to the presence of a great number of $\mathrm{OH}$ groups in the matrix, the enzymes are kept in a hydrophilic environment even in a dry state.

These results show that the best storage stability is obtained by using PVA/SbQ membrane and also that the choice of the storage conditions is greatly influenced by the way in which enzymes are immobilized.

\section{Determination of trichlorfon with BuChE FET sensors}

Figure 7 show that the degree of enzyme inhibition for BSA membrane depends on the trichlorfon concentration and incubation time (only results obtained with BSA membrane are presented because those obtained with PVA membrane are quite similar). Figures 7 a shows a range of detected concentration comprises between $10^{-3} \mathrm{M}\left(0.26 \mathrm{~g} . \mathrm{l}^{-1}\right)$ and $10^{-6} \mathrm{M}$ (0.26 mg. $\left.\mathrm{l}^{-1}\right)$ which corresponds to the values found in the 
literature $[15,25]$. To our knowledge, no exposure limits have been established for trichlorfon in water.

Figure $7 \mathrm{~b}$ shows that the incubation time is an important factor and hence, $30 \mathrm{~min}$ for $\mathrm{BuChE}$ inhibition time will be chosen for further experiments.

\section{Reactivation of enzyme by PAM-2 (BSA membrane)}

As one can see from Fig. 8a, the sensor response was almost reversible for a 10 minutes incubation if the concentration of the pesticide is close to $10^{-5} \mathrm{M}$, whereas for higher concentration $\left(10^{-3} \mathrm{M}\right)$ only a partial recovery of the sensor occurs. From Fig. $8 \mathrm{~b}$, in the case of $10^{-5} \mathrm{M}$ trichlorfon solution, the sensor response was almost reversible for a $10 \mathrm{~min}$ utes incubation with the pesticide solution, whereas after 60 minutes, only a partial recovery of the sensor response occurs. So, the complete recovery of the biosensors response after the performed pesticide assay was possible under certain conditions.

\section{Conclusion}

The successful functionalization of an ammonium FET with a PVC-COOH membrane, by urease and its application to the sensitive determination of urea $(50 \mathrm{mV} / \mathrm{pUrea})$ is reported here. The improvement of urea biosensors based on $\mathrm{pH}$ ISFET using additional layers of charged polymers (Nafion and PVPy) has been shown. The attractive potentialities offered by the ENFET in a differential mode will be exploited for the in vitro measurements of biologically important metabolites.

Two different procedures have been used for the immobilization of enzymes on FET transducer for detecting pesticides. In a first one, enzymes were entrapped in a photocross-linkable PVA/SbQ membrane, while in the second one, enzymes were cross-linked with BSA-glutaraldehyde membrane. Although the both membranes present the same detection limit for trichlorfon $\left(10^{-6} \mathrm{M}\right)$, PVA/SbQ membrane shows a better reproducibility and above all, a longer lifetime. The extension of this work to physico-chemical characterizations such as the membrane permeability or an evaluation either of the electric charge of the membrane or the loss of the enzyme during storage conditions for these both membranes will undoubtedly allow us to better understand the differences observed.

\section{References}

1. Colapicchioni, C.; Barbaro, A; Porcelli, F. Sensors and Actuators B 1992, 6, 202-207.

2. Soldatkin, A.P; El'skaya, A.V.; Shulga, A.A; Netchiporouk, L.I.; Nyamsi Hendji, A.M.; Jaffrezic-Renault, N.; Martelet, C. Anal.Chim. Acta 1993, 283, 695-701.
3. Boubriak, O.A; Soldatkin, A.P.; Starodub, N.F.; Sandrovsky, A.K;.El'skaya, A.K Sensors and Actuators B 1995, 26-27, 429-431.

4. Gorchkov, D.V.; Soldatkin, A.P.; Poyard, S.; Jaffrezic-Renault, N.; Martelet, C. Materials Science and Engineering 1997, C 5, 23-28.

5. Gorchkov, D.V.; Poyard, S.; Soldatkin, A.P.; Jaffrezic-Renault, N.; Martelet, C. Materials Science and Engineering 1997, C 5, 29-34.

6. Pijanowska, D.G.; Torbicz, W. Sensors and Actuators B 1997, 44, 370-376.

7. Alegret, S.; Bartroli, J.; Jiménez, C.; Martìnez-Fàbregas, E.; Martorell, D.; Valdès-Perezgasga, F. Sensors and Actuators B 1993, 15-16, 453-457.

8. Miyahara, Y.; Tsukada, K; Miyagi, H. Sensors and Actuators B 1991, 3, 287-293.

9. Koncki, R.; Leszczynska, E.; Cybulska, A.; Glab, S. Anal. Chim. Acta 1996, 321, 27-34.

10. Skladal, P.; Mascini, M. Biosensors \& Bioelectronics 1992, 7, 335-343.

11. Mionetto, N.; Marty, J.-L.; Karube, I. Biosensors \& Bioelectronics 1994, 9, 463-470.

12. Campanella, L.; Colapicchioni, C.; Favero, G.; Sammartino, M.P.; Tomasseti, M. Sensors and Actuators 1996, B33, 25-33.

13. Dumschat, C; Müller, H.; Stein, K.; Schwedt, G. 1991, 252, 7-9.

14. Dzydevich, S. V.; Shul'ga, A.A.; Soldatkin, A.P.; Nyamsi Hendji, A.M.; Jaffrezic-Renault, N.; Martelet, C. Electroanalysis 1994, 6, 752-758.

15. Nyamsi Hendji, A. M.; Jaffrezic-Renault, N.; Martelet, C.; Cléchet, P.; Shul'ga, A.A.; Netchiporouk, L.I.; Soldatkin, A.P.; Woldarski, W.B. Analytica Chimica Acta 1993, 281, 3-11.

16. Vnavera, E. N.; Suzuki, M.; Yokoyama, K.; Tamiya, E.; Takeuchi, T.; Karube, I. Analytica Chimica Acta 1993, 281, 673-679.

17. Shulga, A.A.; Netchiporouk, L.I.; Sandrovsky, A.K.; Abalov, A.A.; Frolov, O.S.; Kononenko, Ya.G.; Maupas, H.; Martelet, C. Sensors and Actuators B 1996, 30, 101-105.

18. Bergueld, P.; Van Den Berg, A.; Van Der Wal, P.D.; Skowsronska-Ptasinska, M.; Sudhölter, E.J.R.; Reinhoudt, D.N. Sensors and Actuators 1989, 18, 309-327.

19. Senillou, A.; Jaffrezic-Renault, N.; Martelet, C.; Cosnier, S. Talanta (in press).

20. Volotovsky, V.; Soldatkin, A.P.; Shulga, A.A.; Rossokhaty, V.K.; Strikha, V.I.; El'skaya, A.V. Anal. Chim. Acta 1996, 322, 77-81.

21. Van den Berg, A.; Van der Wal, P.D.; Skowronska-Ptasinska, M.; Sudhöler, E.J.R.; Reinhoudt, D.N.; Bergveld, P. Anal. Chem. 1987, 59, 2827-2929.

22. Senillou, A.; Jaffrezic-Renault, N.; Martelet, C.; Griffe, F. Materials Science and Engineering C 1998, 6, 59-63.

23. Shin, J.H.; Yoon, S.Y.; Yoon, I.J.; Choi, S.H.; Lee, S.D.; Nam, H.; Cha, G.S. Sensors and Actuators B 1998, 50, 19-26.

24. Poyard, S. Ph. D. Thèse de doctorat en science, Université Claude Bernard-Lyon I (France), 1996.

25. Marty, J.-L.; Garcia, D.; Rouillon, R. Trends in analytical chemistry 1995, 14 (7), 329-333. 